\title{
P53-HDM2 Protein-protein Interaction Inhibitor APG-115
}

National Cancer Institute

\section{Source}

National Cancer Institute. p53-HDM2 Protein-protein Interaction Inhibitor APG-115. NCI

Thesaurus. Code C132991.

An orally available inhibitor of human homolog of double minute 2 (HDM2; mouse double minute 2 homolog; MDM2), with potential antineoplastic activity. Upon oral administration, the p53-HDM2 protein-protein interaction inhibitor APG-115 binds to HDM2, preventing the binding of the HDM2 protein to the transcriptional activation domain of the tumor suppressor protein p53. By preventing this HDM2-p53 interaction, the proteasome-mediated enzymatic degradation of p53 is inhibited and the transcriptional activity of p53 is restored. This may result in the restoration of p53 signaling and lead to the p53-mediated induction of tumor cell apoptosis. HDM2, a zinc finger protein and a negative regulator of the p53 pathway, is often overexpressed in cancer cells. It has been implicated in cancer cell proliferation and survival. 